\title{
PERAWATAN SALURAN AKAR SATU KUNJUNGAN DISERTAI RESTORASI DAN PASAK RESIN KOMPOSIT PADA NEKROSIS PULPA DENGAN LESI PERIAPIKAL (Terhadap Gigi Insisivus Sentralis Kanan Maksila)
}

\author{
Anung Sri Gutomo* \& Yulita Kristanti** \\ *Program Studi Konservasi Gigi, Program Pendidikan Dokter Gigi Spesialis \\ Fakultas Kedokteran Gigi, Universitas Gadjah Mada, Yogyakarta. \\ **Bagian Konservasi Gigi, Fakultas Kedokteran Gigi, Universitas Gadjah Mada, Yogyakarta.
}

\begin{abstract}
ABSTRAK
Latar belakang. Perawatan Saluran akar satu kunjungan merupakan perawatan saluran akar yang prosesnya diselesaikan dalam satu kali kunjungan. Hal ini memberikan keuntungan antara lain memperkecil resiko kontaminasi mikroorganisme dalam saluran akar dan menghemat waktu perawatan. Pasak resin komposit merupakan pasak buatan sendiri yang dibuat dari resin komposit, pasak ini mempunyai daya tahan yang cukup kuat untuk menerima tekanan pengunyahan dan tidak memerlukan preparasi saluran akar yang banyak membuang struktur dentin.

Tujuan. penulisan laporan kasus ini adalah untuk mengevaluasi restorasi resin komposit dengan pasak resin komposit pasca perawatan saluran akar satu kunjungan pada gigi insisivus sentralis kanan maksila.

Kasus. Laki-laki 20 tahun datang ke Klinik Konservasi Gigi RSGM Prof Soedomo untuk merawatkan gigi depan atas yang berlubang di bagian palatal.

Penanganan. Berdasarkan pemeriksaan subjektif, objektif dan radiografis diperoleh diagnosis gigi insisivus sentralis kanan maksila karies profunda dengan nekrosis pulpa disertai lesi periapikal. Rencana perawatan yang akan dilakukan adalah perawatan saluran akar satu kunjungan, dilanjutkan restorasi resin komposit dengan pasak resin komposit aktivasi kimiawi.

Kesimpulan. Evaluasi klinis pada waktu kontrol gigi insisivus sentralis kanan maksila menunjukkan tidak ada respon perkusi dan palpasi, warna gingiva normal,tumpatan masih utuh, warna tumpatan dan warna gigi tidak berubah. Maj Ked Gi, Juni 2011; 18(1): 39-43
\end{abstract}

Kata kunci: Perawatan saluran akar satu kunjungan, pasak resin komposit, restorasi komposit

\section{ABSTRACT}

Background. Single visit root canal treatment was treatment which finished in single visit. This way give advantage to reduce the risk of microorganism contaminated in root canal and reduce time to treatment.Composite post was fabricated post, had strong resistance to the pressure of mastication and doesn't need over preparation in root canal preparation that can reduce dentin.

Purpose. this case report to evaluate composite restoration with composite post after single visit root canal treatment on maxillary right central incisor.

Case. A male patient 20 years old came to the Conservative Dentistry Clinic of RSGM Prof.Soedomo required treatment of his upper right tooth which decayed on palatal side.

Treatment. According to subjective, objective and radiograph examination, the diagnosis was necrotic pulp with periapical lesion. The treatment planning was single visit root canal treatment, followed by composite resin restoration with composite post chemically activated.

Conclusion. The clinical evaluation throughout follow up revealed was no response to percussion and palpation,no change on gingival colour, no crack on composite restoration, no change on restoration and tooth colour. Maj Ked Gi; Juni 2011; 18(1): $39-43$

Key words: Single visit root canal treatment, composite post, composite restoration.

\section{PENDAHULUAN}

Karies gigi dapat dialami oleh setiap orang dan dapat timbul pada satu permukaan gigi atau lebih. Karies gigi merupakan suatu penyakit jaringan keras gigi, yang melibatkan email, dentin, dan pulpa. ${ }^{1}$ Kerusakan jaringan keras gigi akibat karies apabila dibiarkan tanpa perawatan, bakteri akan berinvasi pada jaringan pulpa yang mengakibatkan kematian pada pulpa, penyebaran infeksi yang berlanjut ke jaringan periapikal yang dapat menyebabkan rasa nyeri dan gigi menjadi nekrosis. ${ }^{2}$

Perawatan untuk gigi yang telah mengalami nekrosis pulpa adalah perawatan saluran akar. Perawatan saluran akar bertujuan untuk membersihkan rongga pulpa dari jaringan pulpa yang terinfeksi, kemudian membentuk dan mempersiapkan saluran akar agar dapat menerima bahan pengisi yang akan 
menutup sistem saluran akar. Hal ini dimaksudkan supaya tidak terjadi kelainan lebih lanjut atau terjadinya infeksi ulang. ${ }^{3}$

Berdasarkan jumlah kunjungan perawatan saluran akar ada dua macam yaitu, Perawatan saluran akar lebih dari satu kunjungan dan perawatan saluran akar satu kunjungan. Pada perawatan satu kunjungan tahapnya sebagai berikut pembersihan saluran akar, sterilisasi dan obturasi dilakukan dalam satu kunjungan. Keuntungan perawatan satu kunjungan antara lain menghemat waktu, menurunkan resiko terjadinya flare up. ${ }^{4}$

Gigi pasca perawatan saluran akar memerlukan perawatan yang berbeda dibandingkan dengan gigi yang masih vital, karena kelembaban yang berkurang serta pengurangan dentin selama perawatan saluran akar yanbg akan mempengaruhi struktur gigi yang masih ada. ${ }^{5}$ Merestorasi gigi yang telah mengalami perawatan saluran akar merupakan pekerjaan yang tidak mudah. Restorasi pada gigi yang telah dilakukan perawatan saluran akar memerlukan bangunan pasak yang dimasukkan ke dalam saluran akar yang menyatu dengan inti. ${ }^{6}$

Nekrosis pulpa adalah matinya pulpa, dapat terjadi sebagian maupun seluruhnya diakibatkan karena inflamasi maupun injuri traumatik. Penyebab nekrosis adalah bakteri,trauma,iritasi dari bahan restorasi silikat, akrilik ataupun inflamasi pulpa yang berlanjut. Mikroorganisme memegang peranan utama pada penyakit pulpa dan periapikal. ${ }^{7}$ Nekrosis pulpa terdiri dari 2 macam yaitu nekrosis koagulasi dan nekrosis likuefaksi. Pada nekrosis koagulasi, bahan jaringan yang dapat larut mengendap atau diubah menjadi bahan solid. Nekrosis liquefaksi terjadi bila enzim proteolitik mengubah jaringan pulpa menjadi masa yang melunak, suatu cairan atau debris amorfus. ${ }^{4}$

Gigi dengan pulpa nekrotik tidak selalu menimbulkan gejala rasa sakit, adanya perubahan warna gigi menjadi keabu-abuan atau kecoklatan seringkali merupakan indikasi kematian pulpa. Bila ada rangsang panas gigi yang nekrosis akan terasa sakit karena terjadi pemuaian gas yang akan menekan ujung saraf jaringan vital yang ada disekitarnya, sedangkan dengan aplikasi dingin (CE) dan stimuli elektrik pada gigi dengan pulpa nekrotik biasanya tidak menimbulkan respon. ${ }^{5}$

Perawatan saluran akar merupakan perawatan biomekanis dan kimiawi sistem saluran akar dengan tujuan nmenghilangkan penyakit pulpa, penyakit periapeks dan mempercepat penyembuhan serta perbaikan penyakit jaringan tersebut. ${ }^{3}$ Perawatan saluran akar dibagi 3 tahap, tahap yang pertama preparasi biomekanis saluran akar, yaitu suatu tahap pembersihan dan pembentukan saluran akar dengan membuka jalan masuk menuju kamar pulpa dari korona, tahap kedua sterilisasi yaitu dengan irigasi dan disinfeksi saluran akar dan tahap yang ketiga adalah pengisian saluran akar. $^{\text {? }}$

Perawatan saluran akar satu kunjungan merupakan perawatan yang prosesnya diselesaikan dalam satu kunjungan. Indikasi perawatan saluran akar satu kunjungan untuk kasus sebagai berikut: 1) pulpa terbuka karena trauma iatrogenik tanpa lesi periapikal, 2) pulpitis ireversibel tanpa lesi periapikal, 3) gigi nekrosis tanpa gejala-gejala klinik disertai lesi periapikal, 4) gigi nekrosis dengan abses periapikal disertai fistula, 5) bentuk saluran akar normal, saluran akar tunggal. Kontraindikasi untuk perawatan saluran akar satu kunjungan 1) adanya rasa sakit pada gigi nekrosis tanpa fistula untuk drainase, 2) gigi dengan kelainan anatomis yang berat, 3) gigi berakar banyak, 4) periodontitis akut dengan rasa sakit parah saat perkusi. ${ }^{5}$

Keuntungan perawatan satu kunjungan antara lain untuk memperkecil resiko kontaminasi mikroorganisme dalam saluran akar, menghemat waktu untuk perawatan, tidak diperlukan medikasi intrakanal dan tumpatan sementara. ${ }^{8}$ Perawatan saluran akar satu kunjungan menghemat waktu perawatan tanpa mengurangi kualitas dari perawatan. ${ }^{9}$

Merestorasi gigi pasca perawatan saluran akar berbeda dibandingkan dengan merestorasi gigi vital, kelembaban internal gigi pasca perawatan saluran akar berkurang sehingga gigi menjadi rapuh, pengurangan dentin selama perawatan saluran akar akan melemahkan struktur gigi yang masih ada. ${ }^{10}$ Perencanaaan restorasi akhir pada gigi pasca perawatan saluran akar harus mempertimbangkan retensi dan resistensi, sehingga restorasi akhir pasca perawatan saluran akar dapat mempertahankan fungsi gigi dalam jangka waktu yang cukup lama. ${ }^{11}$

Pasak adalah bangunan yang dimasukkan ke dalam saluran akar yang berfungsi memperkuat struktur gigi setelah dilakukan preparasi atau disebut juga retensi intraradikular. Salah satu fungsi pasak adalah untuk mendistribusikan tekanan pada jaringan gigi yang tersisa. ${ }^{12}$

Menurut klasifikasinya pasak dapat dibagi menjadi dua kategori yaitu: pasak buatan sendiri dan pasak sediaan buatan pabrik. Pasak buatan sendiri dapat terbuat dari alloy, amalgam,glass ionomer dan resin komposit. Pasak buatan sendiri dapat dibuat secara langsung di dalam mulut pasien saat pasien datang ke klinik maupun tidak lansung dengan membuat model terlebih dahulu. ${ }^{1}$ Pasak buatan sendiri dari bahan resin komposit dapat didesain sesuai dengan bentuk morfologi akar, sehingga pembuangan dentin yang berlebihan dapat dihindari. ${ }^{13}$ Pasak resin komposit tidak memerlukan preparasi saluran akar yang banyak, sehingga dapat mengurangi resiko terjadinya perforasi saluran akar dan struktur detin dapat dipertahankan sebanyak mungkin. ${ }^{14}$ Preparasi saluran akar yang berlebihan untuk penempatan pasak dengan diameter besar akan memperlemah akar, karena kehilangan dentin dapat menyebabkan frak- 
tur akar pada saat menerima beban fungsional. ${ }^{13}$

Pemakaian resin komposit sebagai bahan pasak adalah suatu teknik yang mudah dilakukan, hanya memerlukan satu kali kunjungan, mempunyai estetis yang cukup baik dan jika dikerjakan dengan benar memiliki daya tahan yang cukup kuat untuk menerima tekanan pengunyahan. ${ }^{14}$

Tujuan penulisan laporan kasus ini untuk mengevaluasi restorasi resin komposit dengan pasak resin komposit pasca perawatan saluran akar satu kunjungan pada gigi insisivus sentralis kanan maksila.

\section{LAPORAN KASUS}

Pasien laki-laki, umur 20 tahun, pada tanggal 9 maret 2011 datang ke klinik konservasi gigi RSGM Prof. Soedomo. Pasien ingin merawatkan gigi depan atas yang berlubang pada bagian palatal sejak 3 bulan yang lalu dan belum pernah dirawat oleh dokter gigi. Pasien tidak pernah merasakan sakit dan tidak ada keluhan spontan.

Pada pemeriksaan objektif gigi insisivus sentralis kanan maksila terdapat kavitas sedang yang telah mencapai kedalaman pulpa ( gambar 1). Sondasi, perkusi dan palpasi tidak ada rasa sakit. Tes vitalitas gigi dengan CE negatif ( tidak ada sakit), mobilitas negatif, dan tidak ada diskolorasi pada gigi. Dari pemeriksaan radiografis pada gigi insisivus sentralis kanan maksila terdapat kavitas yang sudah mencapai kamar pulpa. Saluran akar terlihat jelas, tunggal dan lurus dengan area radiolusen diameter $\pm 1 \mathrm{~mm}$ di apikal (gambar 2) .

Diagnosis gigi 11 adalah karies profunda dengan nekrosis pulpa disertai lesi periapikal. Rencana perawatan yaitu perawatan saluran akar satu kunjungan dan dilanjutkan restorasi resin komposit dengan pasak resin komposit aktivasi kimiawi.

Prognosis baik karena saluran akar terlihat jelas, lurus, $\mathrm{OH}$ baik, tidak pernah ada keluhan rasa sakit dan pasien kooperatif.

Kunjungan pertama, 9 maret 2011. Dilakukan pemeriksaan subjektif, objektif, foto intraoral dan radiografis pada gigi insisivus sentralis kanan maksila. Berdasarkan hasil pemeriksaan tersebut, diagnosis gigi insisivus sentralis kanan maksila karies profunda dengan nekrosis pulpa. Perawatan yang akan dilakukan adalah Perawatan saluran akar satu kunjungan dan dilanjutkan restorasi resin komposit dengan retensi intrakanal pasak resin komposit aktivasi kimiawi. Pasien menyetujui tindakan perawatan ini dan pasien menandatangani informed consent.

Tahap pertama adalah pemasangan rubber dam dan saliva ejector. Jaringan karies yang masih tersisa dibersihkan dengan ekskavator dan round metal bur. Dibuat akses masuk ke saluran akar melalui bagian palatal dengan menggunakan endo access bur. Eksplorasi saluran akar menggunakan ja- rum miller kemudian dilakukan debridement jaringan pulpa yang nekrotik. Saluran akar diirigasi dengan $\mathrm{NaOCL} 2,5 \%$ sebanyak $2,5 \mathrm{ml}$.

Tahap berikutnya adalah pengukuran panjang kerja dengan menggunakan metode observasi langsung, diawali dengan menentukan titik referensi di insisal, kemudian mengukur panjang gigi estimasi pada radiograf diagnostik, diperoleh hasil $25 \mathrm{~mm}$. Panjang ini dikurangi $1 \mathrm{~mm}$ sebagai faktor pengaman untuk mencegah terjadinya distorsi. K-file no 15 dengan panjang $24 \mathrm{~mm}$ dimasukkan ke dalam saluran akar hingga stopper terletak pada titik referensi, kemudian dilakukan pengambilan radiograf. Dari hasil radiograf, panjang instrumen pas di apikal gigi, sehingga di dapatkan panjang kerja $24 \mathrm{~mm}$ (gambar 3).

Dilanjutkan preparasi saluran akar dengan metode step back menggunakan K- file. Tahap pertama adalah preparasi daerah 1/3 apikal, Initial apical file (IAF) K- file no 25 dengan panjang kerja 24 $\mathrm{mm}$ Preparasi dilanjutkan dengan dengan K-file no 30 sampai no 50 (Master apical file=MAF) dengan panjang kerja $24 \mathrm{~mm}$, rekapitulasi dengan nomer file dibawahnya dengan PK yang sama. Tahap kedua adalah preparasi badan saluran akar. File yang dipakai adalah file sampai 3 nomer yang lebih besar dari MAF dengan panjang kerja dikurangi $1 \mathrm{~mm}$ setiap kenaikan satu nomer file. Setiap pergantian file dilakukan rekapitulasi dengan file MAF PK $24 \mathrm{~mm}$. Dilakukan coronal flaring menggunakan Hedstroem file no 80 PK $21 \mathrm{~mm}$ dan dilakukan finishing dengan file no 50 PK 24 mm dengan gerakan circumferential filing. Setiap pergantian file dilakukan irigasi dengan menggunakan $\mathrm{NaOCL} \mathrm{2,5 \%} \mathrm{sebanyak} \mathrm{2,5} \mathrm{ml} \mathrm{dan}$ kombinasi dengan EDTA 15\%.Setelah preprasi saluran akar selesai, saluran akar diirigasi dengan larutan klorheksidin $2 \%$ dengan cara digenangi selama 30 detik.

Tahap selanjutnya adalah pengepasan gutta percha sesuai MAF dan dilanjutkan dengan pengambilan radiograf. Pengisian saluran akar menggunakan bahan gutta percha dengan teknik pengisian menggunakan kondensasi lateral. Pada tahap obturasi atau pengisian saluran akar, pertama- tama sealer (topseal, dentsply) dimasukkan ke dalam saluran akar menggunakan lentulo dengan menggunakan handpiece low speed. Gutta percha utama no.50 dioleskan sealer pada 1/3 apikal dan dimasukkkan ke dalam saluran akar. Spreader dimasukkan di antara guttta percha dan dinding saluran akar, kemudian dikondensasikan ke arah apical. Ruang yang tersedia begitu spreader diangkat diisi dengan gutta percha tambahan dengan ukuran lebih kecil, dan dilakukan kondensasi lagi dengan spreader. Penambahan gutta percha tambahan diakhiri sampai sampai spreader tidak dapat masuk lagi ke dalam saluran akar setengah panjang spreader. Gutta percha dipotong sampai batas orifis menggunakan plugger yang dipanaskan dan kemudian dipadatkan. Kavitas 
ditutup dengan menggunakan semen seng fosfat dan tumpatan sementara (orafil G), kemudian dilakukan pengambilan radiograf untuk melihat hasil obturasi saluran akar. Radiograf menunjukkan hasil obturasi yang hermetis( gambar 4).

Kunjungan kedua, 16 maret 2011. Kontrol 1 minggu setelah perawatan saluran akar. Dilakukan pemeriksaan subjektif dan objektif pada gigi insisivus sentralis kanan maksila. Hasil pemeriksaan subjektif, tidak ada keluhan sakit pada pasien, Hasil pemeriksaan objektif, tumpatan sementara masih baik, perkusi dan palpasi negatif, gambaran radiolusen yang menetap.

Perawatan dilanjutkan dengan preparasi saluran pasak, diawali dengan pengambilan gutta percha menggunakan gates glidden drill. Panjang gutta percha yang diambil sepanjang $5 \mathrm{~mm}$ dari orifis, dilanjutkan preparasi pasak menggunakan peeso reamer. Dilakukan Irigasi pada saluran pasak dengan larutan akuades dan dikeringkan dengan paper point. Tahap selanjutnya dilakukan pengaplikasian bonding self etch pada saluran pasak, diaktivasi dengan sinar selama 20 detik. Resin komposit aktivasi kimiawi (core max, dentsply) diinjeksikan ke dalam saluran pasak sampai kira- kira menyisakan ruangan 1-2 mm dari orifis untuk tumpatan resin komposit packable. Setelah resin komposit aktivasi kimiawi mengeras $( \pm 5$ menit), selanjutnya dilakukan preparasi kavitas. Kavitas dibuat hollow ground bevel pada seluruh cavosurface margin dengan menggunakan flame shape bur selebar 1,5 mm. Dilakukan penentuan warna gigi menggunakan Vita lumin shade guide, didapatkan warna A3. Penumpatan bahan resin komposit pada permukaan kavitas,dilakukan secara incremental, setiap lapis diaktivasi dengan sinar selama 20 detik. Prosedur ini dilakukan sampai seluruh permukaan kavitas terisi penuh dengan bahan resin komposit. Finishing restorasi resin komposit menggunakan extra fine finishing bur,kemudian dipoles dengan menggunakan polishing disc (Optidisc, Kerr) dan terakhir menggunakan polishing brush (Optishine, Kerr) (gambar 5). Pasien diinstuksikan datang 1 minggu kemudian untuk kontrol.

Kunjungan ketiga, 23 maret 2011. Kontrol satu minggu pasca restorasi resin komposit. Dilakukan pemeriksaan subjektif dan pemeriksaan objektif. Pada pemeriksaan subjektif, pasien tidak merasakan keluhan sakit. Pada pemeriksaan objektif, perkusi dan palpasi negatif, Tumpatan masih baik, gingival normal, warna tumpatan dan warna gigi tidak berubah, hubungan tepi baik. Pada pemeriksaan radiografis terlihat pasak resin komposit dan restorasi akhir masih terlihat baik,serta lesi periapikal yang menetap (gambar 6).

\section{PEMBAHASAN}

Perawatan saluran akar satu kunjungan pada beberapa kasus cukup menguntungkan diantaranya dapat menghemat waktu kunjungan, meminimalisir kontaminasi bakteri, tidak diperlukan medikasi intrakanal dan tumpatan sementara. Indikasi perawatan saluran akar satu kunjungan untuk kasus sebagai berikut: pulpa terbuka karena trauma iatrogenik tanpa lesi periapikal, pulpitis ireversibel tanpa lesi periapikal, gigi nekrosis tanpa gejala- gejala klinik disertai lesi periapikal, gigi nekrosis dengan abses periapikal disertai fistula, bentuk saluran akar normal, saluran akar tunggal. Kontraindikasi untuk perawatan saluran akar satu kunjungan untuk kasus sebagai berikut: adanya rasa sakit pada gigi nekrosis tanpa fistula untuk drainase, gigi dengan kelainan anatomis yang berat, gigi berakar banyak, periodontitis akut dengan rasa sakit parah saat perkusi.

Teknik preparasi saluran akar yang digunakan pada kasus ini adalah teknik step back, kelebihan teknik ini antara lain lebih efektif membersihkan saluran akar, mempermudah obturasi, Pengisian lebih padat karena spreader dapat menjangkau sampai dekat dengan apeks sehingga mengurangi kebocoran apikal. Kerugian teknik ini antara lain membutuhkan waktu yang agak lama,ukuran saluran akar hasil preparasi biomekanik kecil pada aspek korona, dan pada proses obturasi rentan terjadinya gap baik vertikal maupun horisontal.

Pada kasus ini digunakan bahan irigasi khlorheksidin $2 \%$, karena bahan ini mempunyai sifat antimikroba terhadap enteroccoccus faecalis yang sering menyebabkan terjadinya kegagalan perawatan, selain itu digunakan bahan irigasi sodium hipoklorit $2,5 \%$. Sodium hipoklorit merupakan bahan irigasi meng-andung klorin yang bersifat oksidator dan dianggap paling efektif karena bersifat lubrikan, melarutkan jari-ngan pulpa, pemutih dan antiseptik yang kuat. Selain bersifat bakterisidal, sodium hipoklorit juga virucidal. Konsentrasi $\mathrm{NaOCL}$ yang biasa digunakan adalah berkisar $0,5-5,24 \%$. EDTA $15 \%$ yang digunakan pada kasus ini merupakan agen khelasi yang efektif melunakkan dentin, derajat iritasi sedang, menghilangkan smear layer dan kombinasi dengan $\mathrm{NaOCL}$ akan menaikkan sifat antimikrobanya. Keberhasilan perawatan saluran akar satu kunjungan tergantung dari seleksi kasus yang tepat, ketrampilan operator serta ketaatan terhadap standar prinsip-prinsip endodontik.

Untuk mendukung keberhasilan perawatan saluran akar satu kunjungan diperlukan restorasi yang dapat menjaga keutuhan sisa jaringan yang ada, sehingga pada kasus ini diperlukan adanya tambahan berupa retensi intraradikuler berupa pasak komposit.Pada kasus ini dipilih pasak dari resin komposit aktivasi kimiawi. Resin komposit yang digunakan sebagai pasak termasuk dalam tipe self cured composites, sediaan dalam bentuk syringe terdiri dari pasta dan katalis (two paste chemically activated system), untuk pengerasan membutuhkan waktu 3-6 
menit dari mulai pengadukan. Keuntungan dari pasak resin komposit antara lain tidak memerlukan preparasi yang banyak sehingga struktur dentin dapat dipertahankan sebanyak mungkin, teknik yang mudah dilakukan, hanya memerlukan satu kali kunjungan dan daya tahan terhadap tekanan pengunyahan yang cukup baik.

Pemilihan resin komposit packable sebagai bahan restorasi akhir dengan pertimbangan bahan ini mempunyai kualitas estetik yang baik, polymerization shrinkage yang rendah, serta sifat-sifat mekanis yang memadai antara lain compressive modulus dan flexural modulus yang cukup tinggi,.

Pada kasus ini dilakukan perawatan saluran akar satu kunjungan disertai restorasi resin komposit dengan pasak resin komposit aktivasi kimiawi yang bertujuan untuk menghilangkan penyebab iritan dan mempercepat proses penyembuhan serta mengembalikan fungsi mastikasi, estetik, fonetik dan perlindungan terhadap jaringan pendukung.

\section{KESIMPULAN}

Evaluasi klinis pada waktu kontrol gigi insisivus sentralis kanan maksila menunjukkan tidak ada respon perkusi dan palpasi, warna gingiva normal, tumpatan resin komposit masih utuh, warna tumpatan dan warna gigi tidak berubah.

\section{DAFTAR PUSTAKA}

1. Tarigan R: Perawatan Pulpa Gigi, Penerbit Widya Medika, Jakarta, 1994: 181-194.
2. Eccles JD \& Green RM: Konservasi Gigi (terj), $2^{\text {nd }}$ ed. Penerbit Universitas Indonesia, Jakarta 1994: 145-150.

3. Harty FJ: Endodonti klinis (terj), $3^{\text {rd }}$ ed., Hipokrates Jakarta. 1993: 137-138.

4. Grossman LI, Oliet S, \& del Rio CE: IImu Endodontik Dalam Praktek (terj), $11^{\text {th }}$ ed., Penerbit BukuKedokteran EGC, Jakarta, 1995: 196-380.

5. Ingle JI \& Bakland LK: Endodontics, $5^{\text {th }}$ ed, BC Decker Inc., Hamilton, London. 2002.

6. Shilingburg HT \& Kessler JC: Restoration of the Endodontically Treated Tooth. Quintessence Publishing Co, Chicago. 1982: 13-40.

7. Tri Suhartini: Rawat Ulang Endodontik Gigi Insisivus Lateralis Kanan Atas Dengan Granuloma Diikuti Apikoektomi, Majalah Ceril FKG UGM, 2003.

8. Oliet S: Single Visit Endodontic A Clinical Study, J Endod., 1983;9(4): 147-152.

9. Calhoun RL \& Landers RR: One Appointment Endodontic Therapy: A Nationwide Survey Of Endodontic, J. Endod.,1983; 8(1): 35-40.

10. Baum L, Philips RW, \& Lund MR: Buku Ajar IImu Konservasi gigi (terj). $3^{\text {rd }}$ ed. Penerbit Buku kedokteran, Jakarta. 1997:677-685.

11. Cheung W: A Review of The Management of Endodontically Treated Teeth: Post, core and the final restoration, J Am Dent Ass, 2005; 136: 611-619.

12. Atmajaya G: Pondasi pasak dan inti pada gigi yang telah dirawat endodontik. Majalah IKORGI, Edisi konggres III 1992: 14-28.

13. Cowel CR, curson J, Kantorwicz GF \& Shovelton DS: Inlay, crown and bridge. Bristol: Wright 1985: 106-24.

14. Stahl GJ, O'Neal RB: The composite resin dowel and core. J Prosthet Dent 1975: 329-45.

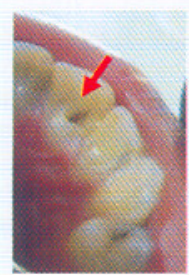

(1)

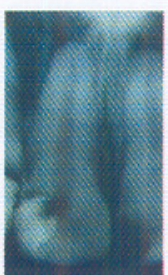

(2)

Gambar 1. Kondisi klinis awal gigi sebelum perawatan.

Gambar 2. Kondisi Radiograf gigi sebelum perawatan.

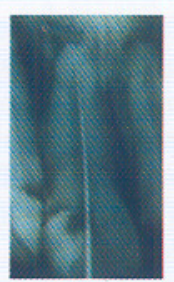

Gambar 3. Radiograf pengukuran panjang kerja

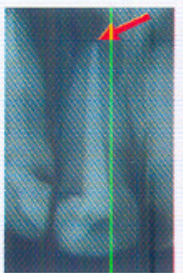

(4)

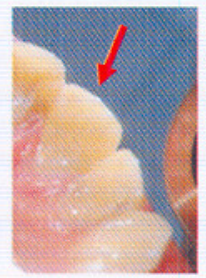

(5)
Gambar 4. Radiograf hasil obturasi, hasil hermetis.

Gambar 5. Restorasi akhir resin Komposit.

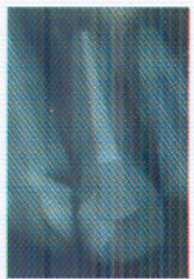

Gambar 6. Gambar radiograf kontrol 1 minggu pasca restorasi akhir 